\title{
DESENVOLVIMENTO DE SISTEMA MÓVEL DE COLETA DE DADOS PARA CONSTRUÇÃO DE ZONAS CLIMÁTICAS LOCAIS
}

\section{DEVELOPMENT OF A MOBILE DATA COLLECTION SYSTEM FOR BUILDING LOCAL CLIMATE ZONES}

\author{
Ernestina Rita Meira Engel ${ }^{1}$; Gabrieli Ozelame Ferrarez²; Pedro Henrique Gonçalves ${ }^{3}$. \\ ${ }^{1}$ Graduação em Arquitetura e Urbanismo, Universidade Federal da Fronteira Sul. \\ ${ }^{2}$ Acadêmica de Arquitetura e Urbanismo, Universidade Federal da Fronteira Sul. \\ ${ }^{3}$ Doutor em Construção Civil, Docente do curso de Arquitetura e Urbanismo, Universidade \\ Federal de Goiás.
}

\section{Palavras Chave}

Desenvolvimento Sustentável; Smart Cities; Zonas Climáticas Locais.

\section{KEY WORDS}

Sustainable Development; Smart Cities; Local Climate Zones.

\section{RESUMO}

O estudo das variáveis climáticas assume importância no cenário atual, através das temáticas de desenvolvimento sustentável e smart cities, que se inserem nas discussões sobre planejamento urbano. O objetivo do estudo é criar um método de coleta de dados para o monitoramento do clima em Goiânia, baseado nas medições de temperatura e umidade, aliado a um sistema de mapeamento. Através da coleta, é possível determinar a existência de alterações no clima e fenômenos climáticos. Com uso de sensores e transectos urbanos, realizou-se o mapeamento da primeira etapa da pesquisa, para verificar as possibilidades de uso do sistema em estudos de classificação a partir da metodologia das Zonas Climáticas Locais, ferramenta auxiliar para a gestão de mudanças climáticas relacionadas à tecnologia de inovação. Como resultados, pode-se concluir que o método de coleta pode ser utilizado para esse os estudos, contribuindo para discussões sobre as alterações climáticas na escala local.

\section{ABSTRACT}

The study of climate variables assumes importance in the current scenario, through the themes of sustainable development and smart cities, which are part of the discussions on urban 


\section{GESTÃO \& SUSTENTABILIDADE AMBIENTAL

planning. The objective of the study is to create a method of data collection for the monitoring of the climate in Goiânia, based on the measurements of temperature and humidity, together with a mapping system. Through the collection, it is possible to determine the existence of changes in climate and climatic phenomena. With the use of sensors and urban transects, the mapping of the first stage of the research was carried out to verify the possibilities of using the system in classification studies based on the methodology of Local Climate Zones, an auxiliary tool for the management of climate changes related to innovation technology. As results, it can be concluded that the collection method can be used for this study, contributing to discussions on climate change at local scale. 


\section{INTRODUÇÃO}

Uma das questões mais relevantes em discussão no ambiente acadêmico e governamental atual é a preocupação com o rumo que o desenvolvimento das cidades, estados e países está seguindo (LOPES, 2016). Este debate é pertinente uma vez que o crescimento populacional no Brasil, nas últimas décadas, ocasionou um cenário de degradação social e ambiental, onde o descompasso entre os investimentos públicos em infraestrutura, o rápido processo de urbanização e a ausência de um planejamento capaz de suprir as necessidades da população provocaram graves danos no sistema urbano nacional.

Em decorrência desta situação, aplica-se o conceito de desenvolvimento sustentável, apresentado pela primeira vez em 1987 como a ação que satisfaz as necessidades do presente sem comprometer a capacidade das gerações futuras de satisfazer suas próprias necessidades (EDWARDS, 2008). O termo é utilizado como forma de padronizar estudos que visam a redução das problemáticas supracitadas a partir do entendimento das fragilidades do modelo vigente e da emergente necessidade de uma nova concepção de desenvolvimento de forma justa, ecológica e equitativa.

O fortalecimento dos processos de gestão se mostra fundamental para resgatar e manter a qualidade do ambiente urbano, bem como de seus habitantes. Todavia, promover as condições de sustentabilidade ao mesmo tempo em que permita seu desenvolvimento, torna-se improvável sem a existência de instrumentos capazes de auxiliar os pesquisadores na incorporação de práticas do desenvolvimento urbano sustentável na sociedade (LOPES, 2016).

Diante desse contexto, o presente estudo concentra-se em um desses instrumentos auxiliares: as Zonas Climáticas Locais (ZCLs). Esse método de classificação leva em consideração dados detalhados de cada recorte de estudo, visando uma análise minuciosa das intempéries climáticas e os fatores que as impulsionaram, com o objetivo de encontrar soluções específicas e efetivas. Todavia, o processo de coleta dos dados adotado por grande parte dos pesquisadores é baseado em bancos de dados mundiais, os quais infelizmente não abrangem a área deste estudo.

Os levantamentos de dados em níveis específicos contribuem com ampliação de análises com foco nas problemáticas locais. A metodologia de Zonas Climáticas Locais leva em conta inúmeros fatores que aumentam a complexidade do processo, desde a forma de coleta ao tratamento posterior dos dados. Entretanto, é uma metodologia que traz detalhamento de resultados, devido ao trabalho com áreas específicas. Esse processo permite chegar a um grande detalhamento, que possibilita inúmeras análises com base nas variáveis e dados levantados.

Dessa forma, o objetivo principal do artigo é construir um método de coleta móvel, personalizável, simples e acessível, onde seja possível realizar o levantamento e armazenamento dos dados necessários para a classificação das ZCLs, a qual realizar-se-á em estudos futuros. Para isso, o recorte analisado foi o Campus Samambaia da Universidade 


\section{GESTÃO \& SUSTENTABILIDADE AMBIENTAL \\ sunisul}

Federal de Goiás (UFG), localizado na cidade de Goiânia no estado de Goiás (Figura 1). privadas, visando o uso racional de seus recursos financeiros, visto que ao implantar
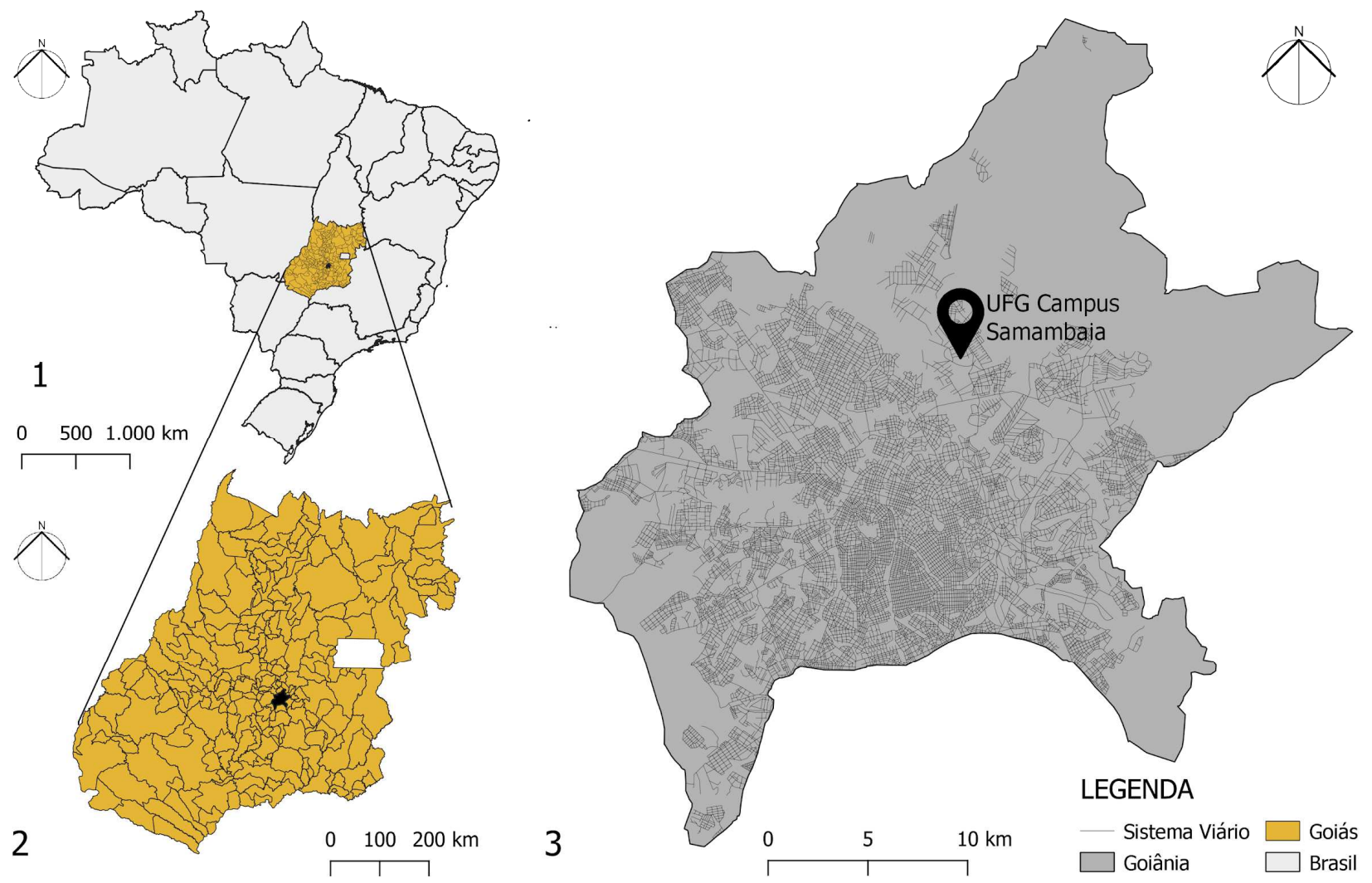

Figura 1. Mapa de localização de Goiás no Brasil (1), localização de Goiânia no estado de Goiás (2) e localização do Campus UFG em Goiânia (3).

Fonte: Elaborado pelos autores, 2021, a partir da base de dados SIEG (2015).

O método de classificação em Zonas Climáticas é uma das iniciativas que compõem as smart cities, um modelo de gestão com integração entre tecnologia e desenvolvimento sustentável, contribuindo diretamente com a preservação ambiental e na qualidade de vida das pessoas, através da otimização das tarefas diárias relacionadas à mobilidade urbana, trabalho, entretenimento e educação (LINDSKOG, 2016). Ademais, a adesão de sistemas inteligentes em planejamentos urbanos é uma das soluções mais racionais a ser adotada por administrações públicas e sensores e dispositivos automatizados para monitoramento, a ocorrência de problemas tende a ser menor e com detecção e resolução rápidas, reduzindo custos e permitindo a alocação de investimentos para outras áreas (DIAS; SEIXAS, 2018).

\section{FUNDAMENTAÇÃO TEÓRICA}

\subsection{Desenvolvimento Sustentável}

O desenvolvimento sustentável, como entende-se atualmente, emergiu na década de 60, quando os efeitos negativos da evolução 
industrial ao meio ambiente começaram a ser notados e denunciados pela sociedade (BRAGA, 2010). A primeira manifestação ocorreu em 1962, com a publicação do livro Primavera Silenciosa, da cientista e ecologista Rachel Carson. O texto evidenciou a necessidade por debates em torno da questão ambiental, apresentando provas de que as consequências desse novo estilo de vida, baseado na produção e consumo, estavam afetando negativamente o cotidiano de todos os cidadãos, mesmo que aparentemente ainda fossem sinais imperceptíveis (PRESTES, 2010).

A partir disso, inúmeros grupos e nações preocupados com a pauta do desenvolvimento urbano iniciaram seus atos, como a Conferência da Biosfera e a criação do Clube de Roma, ambos em 1968, além da Conferência das Nações Unidas sobre Meio Ambiente, realizada em 1972 (BRAUN, 2005). As discussões nesses eventos eram voltadas para os impactos e ações na esfera ambiental, a fim de fomentar pesquisas sobre ecossistemas, ecologia e poluição. De acordo com Guilhon (2011), somente a partir da Conferência Rio 92 os discursos sobre desenvolvimento urbano sustentável expandiram seus conceitos além da questão ambiental, e agregaram mais 4 aspectos: social, econômico, cultural e político.

Dessa forma, elaborou-se um documento que determinava o novo padrão de desenvolvimento a ser seguido no século XXI: a Agenda 21 (NOBRE, 2000). Após a consolidação dos resultados de tal documento, em 2015 foi aprovada pela ONU Organização das Nações Unidas - a Agenda
2030, um novo conjunto de metas divididas em 17 Objetivos de Desenvolvimento Sustentável (ODS), sendo os principais relacionados à erradicação da pobreza, cidades e comunidades sustentáveis, saúde bem-estar, igualdade de gênero e água potável e saneamento (LOPES, 2016). O ODS 11, sobre as cidades e comunidades sustentáveis, está relacionado diretamente com outro termo que provém das abordagens contemporâneas de desenvolvimento urbano: as smart cities (CURY; MARQUES, 2016).

Dessa forma, pode-se afirmar que o desenvolvimento sustentável busca a correta utilização dos recursos atuais, sem comprometer a existência destes recursos para as gerações futuras. Para alcançar esse objetivo, é necessário a compatibilização de alguns aspectos, que são: a viabilidade econômica, a superação da pobreza e índices de desigualdade, a preservação ambiental e da biodiversidade, governanças democráticas, além da limitação do uso de recursos nãorenováveis (UNIVERSIDADE LUTERANA DO BRASIL, 2009).

Tendo esses conceitos como ponto de partida, é importante salientar que existem diversos desafios atualmente para a concretização de uma sociedade com desenvolvimento sustentável. Uma das limitações está nos modos de mensurar o desenvolvimento sustentável, e também a sustentabilidade ambiental, em um aspecto mais amplo. No caso do desenvolvimento sustentável, estão incluídos aspectos para além do meio ambiente, como aspectos sociais, políticos, culturais e econômicos. Todas essas dimensões devem ser analisadas em conjunto, 
garantindo instrumentos que permitam $o$ planejamento, a pesquisa científica e a criação de políticas públicas sobre o tema (UNIVERSIDADE LUTERANA DO BRASIL, 2009).

\subsection{Smart Cities}

O termo cidade inteligente, tradução para o português, ganhou destaque em meados de 1999 (STRAPAZZON, 2009) e pode ser definido como "áreas com alta capacidade de aprendizagem e inovação construídas com base na criatividade de sua comunidade, de suas instituições e de sua infraestrutura digital para a comunicação e gestão do conhecimento" (KOMNINOS, 2008). Atualmente, as pesquisas na área estão crescendo, devido às problemáticas enfrentadas pelas cidades e grandes centros atualmente.

As smart cities exercem um processo de renovação e recriação associado ao uso das tecnologias de informação e de comunicação (TICs), com o escopo de "monitorar, compreender, analisar e planejar seu desenvolvimento, aumentando a eficiência, os investimentos e a qualidade de vida dos cidadãos em tempo real" (BATTY et al., 2012). Para atingir este conceito, existem quatro fases, sendo elas: fase vertical (aplicação de tecnologia aos serviços para melhorar a gestão), fase horizontal (desenvolvimento de uma plataforma de gestão), fase conectado (conexão dos diversos serviços, que passam a operar na plataforma), e por fim, a fase inteligente (onde a cidade é gerenciada de forma integrada e em tempo real) (CUNHA et al., 2016).

\section{১unisul}

Nesse ínterim, a abordagem de cidades inteligentes inclui tecnologias que

"[...] promovem maior eficiência energética e otimização na produção de bens e serviços; sistemas inteligentes para o monitoramento e gerenciamento das infraestruturas urbanas e antecipação de acidentes naturais; sistemas especializados de atenção à saúde e educação que permitem a interação com os atores por intermédio da internet; sistemas, métodos e práticas para o gerenciamento integrado de serviços de qualquer natureza; sistemas para o tratamento de grandes volumes de dados estruturados e não estruturados; sistemas de georreferenciamento; tecnologias de identificação por radiofrequência e etiquetas digitais colocadas em produtos e cargas, otimizando os processos logísticos e as transações comerciais; sensores e sistemas de inteligência artificial que percebem e respondem rapidamente a eventos ocorridos no mundo físico, desencadeando processos digitais que passam a ter consequências cada vez mais imediatas e significativas no mundo, conectando pessoas, empresas e poder público a qualquer tempo e em qualquer lugar" (WOLFRAM, 2012).

Dessa forma, no âmbito das pesquisas sobre cidades inteligentes, as variáveis climáticas e o monitoramento adquirem importância fundamental, sendo um instrumento significativo para a melhoria do ambiente urbano. Assim, em combinação com outros parâmetros e análises, os dados climáticos são fundamentais, sendo uma ferramenta significativa para a gestão e controle dos efeitos negativos das mudanças climáticas em áreas urbanizadas. 


\subsection{Zonas Climáticas Locais}

Ao longo dos anos, inúmeros estudos foram desenvolvidos a fim de contribuir com a elaboração de novas formas e tecnologias para o gerenciamento das cidades (WEISS; BERNARDES; CONSONI, 2015), dentre elas a metodologia de classificação baseada em Zonas Climáticas Locais (ZCLs). Desenvolvidas por Stewart e Oke, são definidas como "regiões com estrutura, materiais, atividades humanas e cobertura de superfície uniformes que se estendem por centenas de metros horizontalmente" (STEWART; OKE, 2012).

As ZCLs foram propostas como uma forma de detalhar informações climáticas de propriedades específicas, visando classificar as paisagens em fichas técnicas através de características homogêneas. Além disso, objetiva complementar a tradicional diferenciação entre área urbana e rural, visto que são termos que não descrevem suficientemente um local e seus arredores, pois cada paisagem possui propriedades singulares que influenciam no clima e proporcionam diversas anomalias térmicas (STEWART; OKE, 2012).

A princípio, o modelo de classificação foi desenvolvido para a investigação dos efeitos das ilhas de calor urbanas (ICUs), mas através dos dados coletados e as metodologias adotadas em inúmeros estudos, foi possível concluir que tal esquema permite a análise de outros efeitos da estrutura térmica urbana, como a aerodinâmica do vento, concentração de poluentes na atmosfera, índices de conforto, disponibilidade de umidade, entre outros. (FERREIRA, 2019).

A metodologia leva em conta diversos parâmetros de análise, compostas por 17 classes padrão, as quais se dividem em 2 grupos: um de tipologias construídas, e outro de tipologias de cobertura do solo (STEWART; OKE, 2012). Os fatores abordados pela metodologia são: admitância de superfície, albedo superficial, saída de calor antropogênico, fator visão do céu, fração de superfície permeável, fração de superfície impermeável, altura dos elementos de rugosidade, classe de rugosidade do terreno, relação H/W e fração de superfície edificada. Assim, os parâmetros possuem como base características físicas (geométricas e de cobertura superficial), térmicas, radiativas e metabólicas (DAVENPORT et al., 2000).

\section{METODOLOGIA}

A metodologia do trabalho é dividida em 4 etapas principais, sendo elas: definição do polígono de estudo, levantamento de campo, sistematização dos dados para produção de mapas e publicação dos resultados. Para as análises, foi definido um polígono de estudo correspondente ao Campus da Universidade Federal de Goiás, em Goiânia.

O local foi escolhido por possuir áreas distintas na malha urbana (Figura 2), como áreas de preservação de matas ciliares, áreas edificadas, paisagismo construído pelo homem, proximidade com um parque dentre outros aspectos urbanos, configurando a possibilidade de diferentes valores ambientais em uma pequena parcela urbana. 

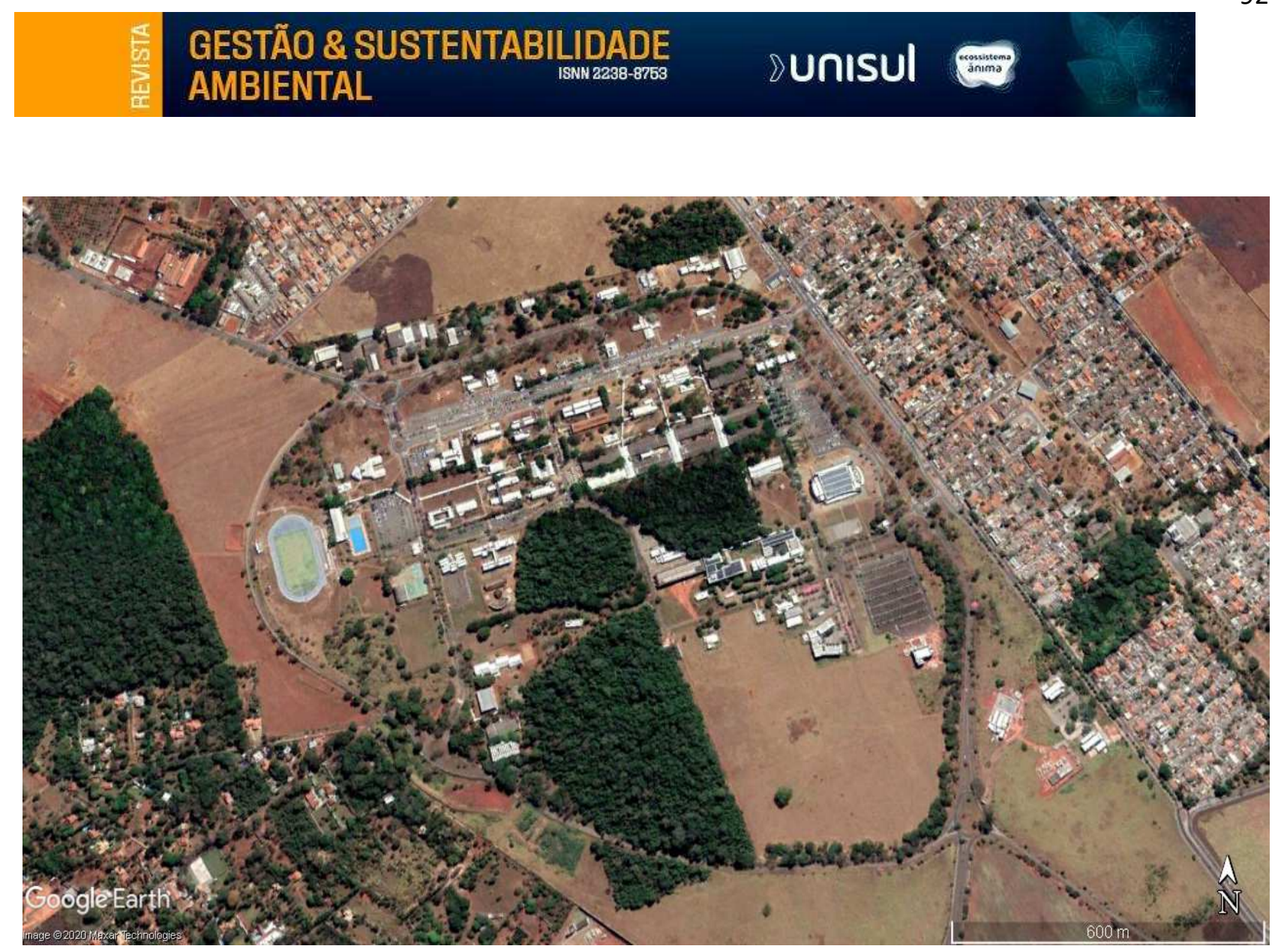

Figura 2: Mapa Campus Samambaia (UFG).

Fonte: Elaborado pelos autores, 2021, a partir do Google Earth Pro, 2019.

Para o levantamento de dados, foi construído um sistema embarcado móvel constituído de um microcontrolador Arduino UNO, um sensor de temperatura e umidade DHT22, um módulo GPS NEO6M, um módulo de leitor e gravador de dados SD para função de datalogger e uma bateria de $9 \mathrm{~V}$ (Figura 3). A programação do sistema foi feita no IDE do Arduino, com a gravação programada a cada 15 segundos. A coleta de dados gera um conjunto de informações sobre cada ponto, como horário da coleta, latitude e longitude, precisão, altitude, velocidade, temperatura e umidade. Levando em conta que atualmente não existem equipamentos semelhantes no mercado, o protótipo apresenta-se como uma inovação no campo de coletas de dados.

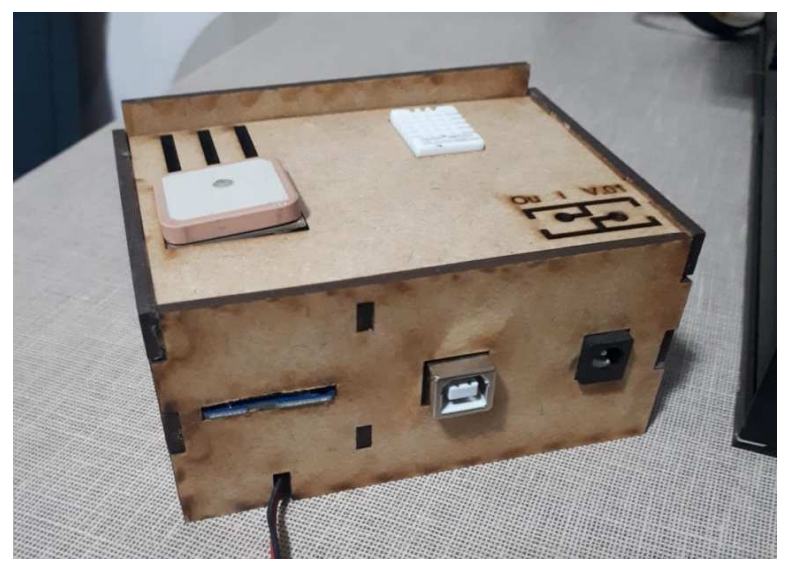

Figura 3: Medidor de variáveis móvel.

Fonte: acervo dos autores, 2021.

Após, ocorreu a etapa de sistematização dos dados e produção de mapas, onde houve a 
classificação dos dados da coleta de campo e o posterior processamento em softwares que atuam com sistemas SIG/GIS. Os softwares utilizados foram o Quantum Gis (QGis). O software é livre, e possui uma multiplataforma que possibilita a edição, visualização e análise de dados georreferenciados. Foi utilizado também o software ArcMap, que pertence à plataforma ArcGis. Ele pode ser utilizado para criação, edição e análise de dados geoespaciais. Cada vez mais, as ferramentas de geoprocessamento estão sendo utilizadas para estudos urbanos e ambientais, por oferecerem diversas possibilidades para criação de mapas, processamento de dados e imagens, e análises espaciais.

Através dos dados obtidos no levantamento, em conjunto com ferramentas de coleta de coordenadas geográficas dos pontos de estudo, foi possível realizar a espacialização dos dados de temperatura e umidade do trajeto. Com isso, foi gerado o mapa de pontos para visualização. O passo seguinte foi a geração da imagem, resultado da interpolação dos pontos, a partir dos dados de temperatura e umidade.

Para os resultados, foi utilizada a ferramenta de interpolação Natural neighbor, do programa ArcMap. Segundo Sibson (1981, apud ARCMAP, 2020), o algoritmo da ferramenta Natural Neighbor é utilizado para encontrar o subconjunto de amostras de entrada mais próximo de um ponto de consulta, aplicando pesos para cada um com base na definição de áreas proporcionais aos valores, para assim gerar o valor de interpolação. Esse tipo de interpolação se apresenta útil na configuração de imagens a partir de pontos dispersos, sendo eles regulares ou não. A ferramenta foi escolhida devido a possibilidade de criar áreas homogêneas, na forma de manchas, que reúnam as mesmas características de temperatura e umidade, a fim de visualizar onde os valores climáticos são os mesmos.

Para a etapa de publicação dos resultados, utilizou-se, dentro do programa QGis, o plugin Qgis2Web, que permite a exportação dos mapas para web. A partir do plugin, é possível criar mapas com diversas camadas, permitindo sobreposição de dados, com informações dinâmicas.

Através disso, objetiva-se criar uma plataforma, onde os mapas e os dados coletados possam ser acessados, tornando os estudos disponíveis em acesso público, para pesquisadores da área, e também para a comunidade geral e gestores, onde a pesquisa possa servir de subsídio para futuras tomadas de decisão quanto a políticas climáticas.

\section{RESULTADOS E DISCUSSÃO}

O primeiro passo da pesquisa foi a realização do levantamento dos dados in loco, com o equipamento desenvolvido. Buscou-se a construção de um sistema fácil e acessível, permitindo, ao mesmo tempo, a coleta de dados climáticos e as coordenadas espaciais de cada ponto.

O medidor realizado é de baixo custo e fácil montagem. Como forma de levantar os custos da construção do medidor de variáveis móvel, foi realizada pesquisa no site Mercado Livre. A partir da busca dos valores, foi realizada média simples entre três fornecedores do 
mesmo produto. A consulta foi realizada em junho de 2021. Dessa forma, chegou-se ao valor médio de construção do equipamento de $\mathrm{R} \$ 155,85$, como demonstra a Tabela 01.

Tabela 01: Custos médios do equipamento

\begin{tabular}{|c|c|}
\hline $\begin{array}{r}\text { Custo médio dos equ } \\
\text { necessários para construç } \\
\text { variáveis mó }\end{array}$ & $\begin{array}{l}\text { nentos } \\
\text { nedidor de }\end{array}$ \\
\hline $\begin{array}{l}\text { Microcontrolador Arduino } \\
\text { UNO }\end{array}$ & $\mathrm{R} \$ 27,99$ \\
\hline $\begin{array}{l}\text { Sensor de Temperatura e } \\
\text { Umidade DHT22 }\end{array}$ & $\mathrm{R} \$ 43,00$ \\
\hline Módulo GPS NEO6M & $\mathrm{R} \$ 58,63$ \\
\hline $\begin{array}{l}\text { Módulo de leitor e } \\
\text { gravador de dados SD }\end{array}$ & $\mathrm{R} \$ 12,46$ \\
\hline Bateria de 9V & $\mathrm{R} \$ 13,76$ \\
\hline Total & $\mathrm{R} \$ 155,85$ \\
\hline
\end{tabular}

Dessa forma, chegou-se a um custo baixo de execução, o que torna possível a construção do equipamento e ampliação do acesso a pesquisa com esse tipo de medidor. É essencial buscar formas acessíveis de construir equipamentos, permitindo que novas pesquisas possam ser realizadas. Além disso, o aparelho é adaptável, e apresenta diversas possibilidades de incorporação de outros sensores para coleta de dados, como, por exemplo, de poluição ambiental.

Quanto à envoltória do equipamento, o case foi construído com Medium Density Fiberboard (MDF), com o uso de uma CNC a laser. Porém, para os próximos protótipos, há a intenção de se construir utilizando impressão $3 \mathrm{~d}$ com o uso do copolímero Polietileno Tereftalato de Etileno Glicol (PETG), por possuir características de resistência à temperatura superior ao MDF empregado no equipamento. Ainda, vale ressaltar que as duas técnicas mencionadas fazem parte da inovação industrial 4.0 de manufatura avançada, possibilitando a criação e construção de sistemas personalizados e de forma mais sustentável e com bom resultado final.

Com a realização do levantamento, foi possível perceber que o sistema embarcado, no geral, apresentou um bom funcionamento durante a coleta e na geração dos dados. Durante o processo, é possível gerar um conjunto de informações de cada um dos pontos espaciais, para posterior tratamento. Assim, o equipamento capta o horário da coleta, as coordenadas geográficas (latitude e longitude), precisão, velocidade, além da temperatura e umidade local, que serão os principais dados analisados na criação de mapas categorizados.

A figura 4 ilustra o arquivo de texto (.txt) que é gerado no cartão de memória com os dados coletados. No total, foram coletados 248 pontos. Deste total, apenas 9 das leituras apresentaram algum tipo de falha na coleta dos valores de temperatura e umidade, sendo desconsiderados para a posterior classificação. Acredita-se que isso aconteceu nestes pontos devido a um erro de sincronia entre o horário coletado pelo sistema de GPS e o tempo programado para a leitura dos valores de temperatura e umidade. Entretanto, pelo baixo número de valores inválidos, e também pelo 
pequeno tempo entre as coletas de cada ponto, não houve prejuízos significativos nos resultados finais. aeroporto se encontra, com menos vegetação e mais áreas impermeabilizadas com asfalto.

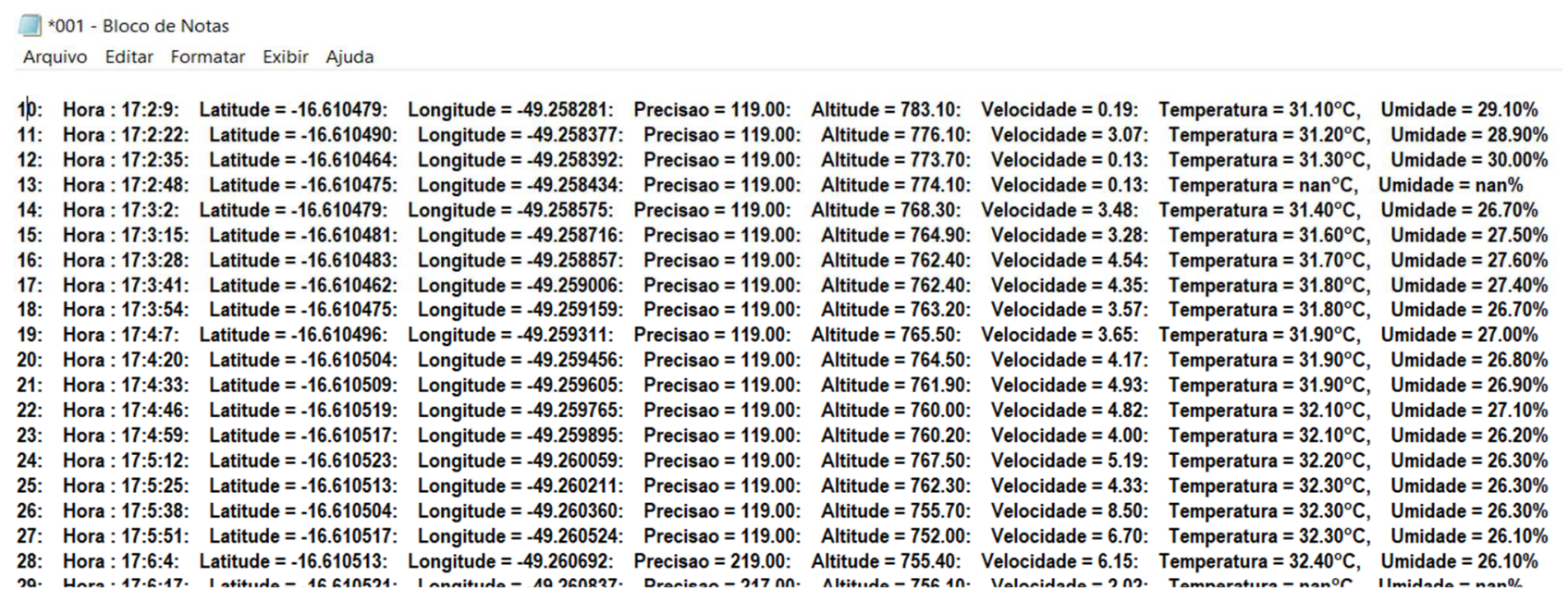

Figura 4: Exemplo do arquivo de coleta de dados.

Fonte: Acervo dos autores, 2021.

A partir da coleta de dados, realizada no dia 13 de setembro de 2020 , das $17 \mathrm{~h}$ às $17 \mathrm{~h} 56$, no trajeto definido, obteve-se o levantamento dos valores de temperatura e umidade do local.

Em comparação à temperatura média da estação automática localizada no aeroporto Santa Genoveva para a data e horário, a qual era de $31^{\circ}$, observa-se que a precisão do sensor utilizado é boa e pode ser considerado como base para os estudos, já que possui valores semelhantes (média de 32 graus no sistema móvel).

O valor de umidade média da estação coletada foi de $19 \%$, enquanto a média medida no local foi de $26 \%$. Essa variação pode ser explicada pelo contexto urbano das duas localizações. O campus universitário da UFG localiza-se na periferia da cidade, com um contexto de paisagem com vegetação mais presente em relação ao contexto onde o
A partir do mapa de pontos categorizado é possível identificar os dados de temperatura e umidade. Conforme observa-se na Figura 5, as áreas próximas à pista de atletismo apresentam temperaturas elevadas e os índices de umidade são mais baixos, pois a cobertura do solo é escassa em relação às demais áreas do percurso, sem nenhuma arborização. Já nas redondezas do entroncamento da via de trânsito, a temperatura vai diminuindo concomitante ao aumento da umidade relativa do ar, visto que o percurso é arborizado e, em certas regiões, com a presença de pequenos bosques, evidentemente melhorando o microclima do local. 


\section{GESTÃO \& SUSTENTABILIDADE

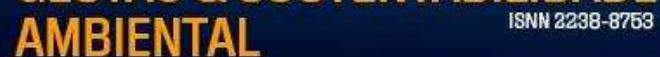 \\ ১unisul 5}

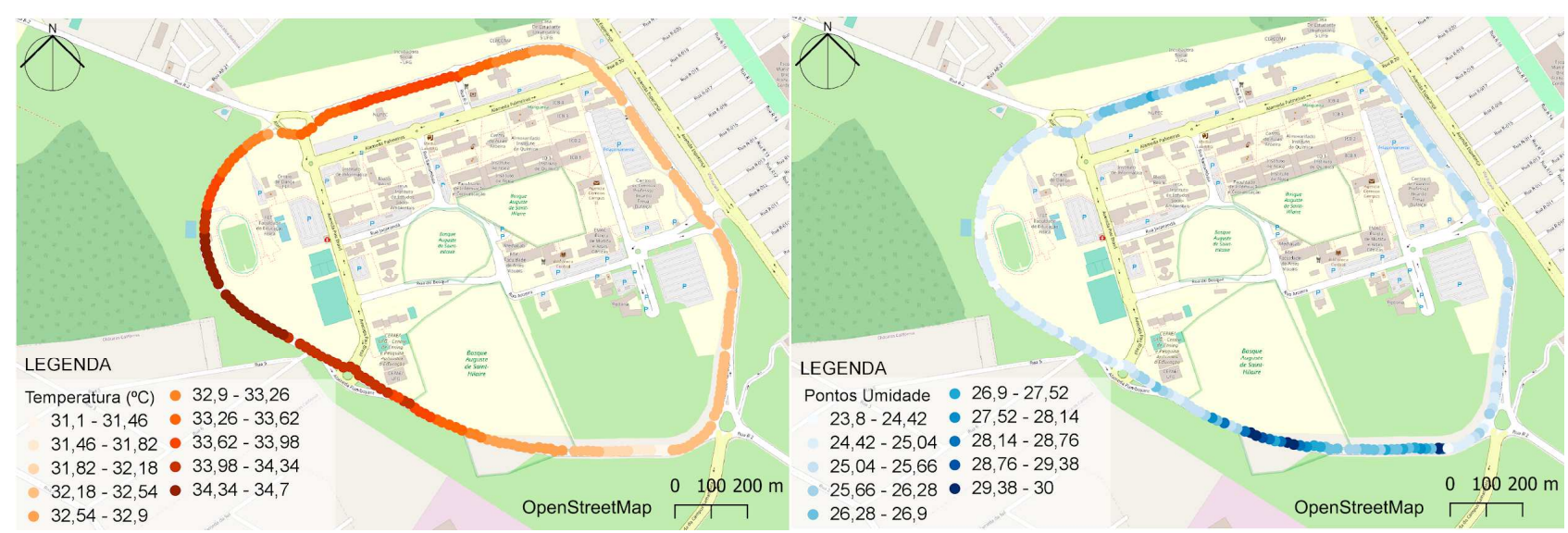

Figura 5: Resultado dos dados de coleta de temperatura e umidade.

Fonte: Elaborado pelos autores, 2021. Mapa base OpenStreetMaps.

Como o objetivo do estudo é desenvolver um método de coleta de dados para a posterior classificação da área em Zonas Climáticas Locais, o levantamento desses valores e a localização dos pontos fazem parte da primeira etapa desse processo. Essa etapa é importante para a identificação das dinâmicas climáticas na escala local, e fornece informações relevantes para as análises seguintes.

Deste modo, posteriormente, para que seja possível coletar os dados tabelados pelos autores Stewart e Oke (2012), desenvolvedores das ZCLs, é necessário transformar os pontos em grupos que compreendam todo o recorte de estudo. Deve-se levar em consideração que essa união em grupos deve cumprir com a premissa da classificação, que é uma análise não generalizada dos locais.

À vista disso, através da aplicação da interpolação dos valores coletados, foi possível determinar as zonas levando em consideração áreas com a mesma variação térmica e mesma variação de umidade (Figura 6), onde constatase que, apesar do recorte de estudo ser de pouco mais de 117 hectares, considerado pequeno em comparação a área total da cidade de Goiânia, as variações apresentadas são bem significativas.

Isso posto, ao todo foram geradas um total de 5 classes de temperaturas e 7 classes de umidade. Como pode ser observado, a temperatura máxima encontrada foi de $34,7^{\circ} \mathrm{C}$, e a mínima $31,2^{\circ} \mathrm{C}$. Já com relação a umidade, a variação vai de $24,3 \%$ a $29,64 \%$, maior em comparação com a temperatura. 


\section{GESTÃO \& SUSTENTABILIDADE AMBIENTAL \\ ১unisul}

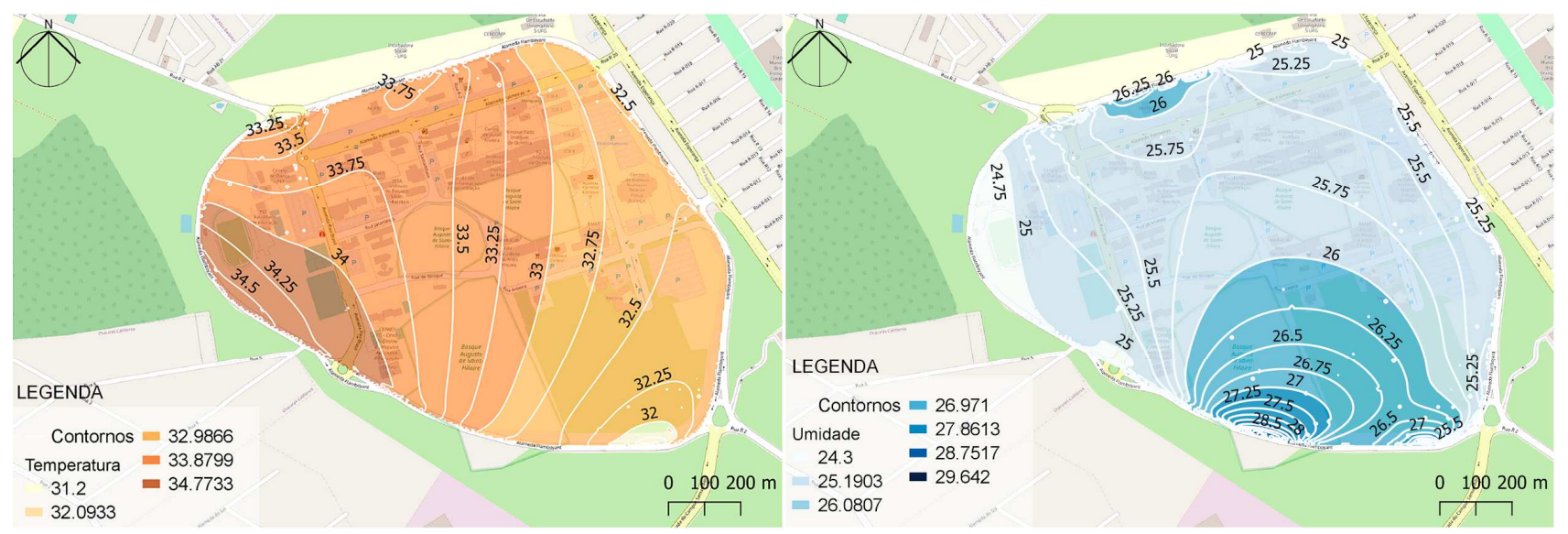

Figura 6: Resultado da interpolação dos dados de temperatura e umidade.

Fonte: Elaborado pelos autores, 2021. Mapa base OpenStreetMaps.

As diferenças ocorrem, principalmente, devido aos fatores de urbanização e influência antrópica, como a cobertura do solo e massas vegetais do entorno. Assim, confirma-se a influência desses dois fatores na temperatura percebida em cada local, com variações consideráveis em uma pequena parcela urbana.

Outro ponto importante levantado com a pesquisa é que, a partir do levantamento, podese observar que é possível utilizar o sistema para esse tipo de coleta, tanto em escalas locais, ou microescala, quanto em escalas mais abrangentes, que englobam a área urbana como um todo.

O método se apresenta como uma possibilidade de baixo custo e com resultados positivos quanto à qualidade dos dados da coleta. Por considerar apenas informações coletadas na hora e no local, possibilita aos usuários ou gestores que o adotarem um levantamento com precisão em qualquer recorte de estudo.
O estudo também avaliou a possibilidade de compartilhamento dos resultados em plataformas online. Assim, após o processamento e exportação dos dados a partir do software QGis, o mapa foi disponibilizado no site labam.dev, do Laboratório do Ambiente (UFG). A página da web é o local onde são divulgados os resultados de diversas pesquisas realizadas pelos membros do laboratório e parceiros. A proposta da divulgação é que os dados possam ser transformados em informações para planejadores urbanos e gestores, a fim de subsidiar estudos futuros.

Em trabalhos futuros, tem-se a ideia de aumentar a quantidade de sensores e dados, coletando mais informações sobre os recortes de estudo. Além disso, pretende-se criar um sistema que possa ter conexão direta com a internet, com o compartilhamento dessas informações para rápida visualização e análises. Isso posto, o método permitirá análises mais eficientes e em um menor intervalo de tempo, além de possibilitar a criação de sistemas de monitoramento 
interativos a partir das coletas realizadas em campo.

\section{CONSIDERAÇÕES FINAIS}

O estudo teve como função principal avaliar a possibilidade do desenvolvimento de um sistema de coleta móvel, da construção de mapas georreferenciados e da divulgação dos dados através de páginas da web. A possibilidade de criação de equipamentos personalizados para medições de monitoramento oferece diversas oportunidades quanto a melhorias de métodos de coleta e análise de dados climáticos. Enquanto isso, a divulgação dos resultados através de plataformas interativas e de acesso público visa facilitar o acesso aos dados, auxiliando no embasamento de decisões políticas relacionadas ao planejamento urbano e melhoria da qualidade de vida, além de cooperar com outros estudos acadêmicos relacionados ao assunto.

A metodologia de Zonas Climáticas Locais é uma ferramenta importante para análises específicas e conclusivas desde a micro até a macro escala. Assim, constitui-se como uma importante ferramenta para a área de planejamento urbano e desenvolvimento sustentável. As variáveis abordadas pelas análises influenciam diretamente os efeitos climáticos, podendo ser a fonte para um banco de dados que busca o monitoramento e a gestão das mudanças climáticas, que possibilitaria uma melhora na qualidade ambiental dos espaços urbanos.

Em estudos futuros, o foco será no aprofundamento das análises e construção das Zonas Climáticas Locais, envolvendo todas as variáveis da sua metodologia. A análise e construção de estudos sobre a classificação em zonas climáticas vem a contribuir para a gestão baseada no desenvolvimento sustentável, visto que através dos resultados obtidos na coleta de dados específicos e análises minuciosas da área abordada pela pesquisa, é possível desenvolver medidas reparadoras e preventivas que devem ser tomadas a fim de minimizar os efeitos climáticos urbanos, bem como elevar a qualidade dos ambientes e garantir investimentos públicos conscientes e efetivos.

\section{REFERÊNCIAS}

ARCMAP. How Natural Neighbor works. Disponível em: https://desktop.arcgis.com/en/arcmap/10.3/too 1s/spatial-analyst-toolbox/how-naturalneighbor-works.html. Acesso em agosto de 2020.

BATTY, M. et al. Smart cities of the future. European Physical Journal: Special Topics, 481-518. doi: 10.1140/epjst/e2012-01703-3. 2012.

BRAGA, R. Política Urbana e

Desenvolvimento sustentável: Avanços e Limites do Estatuto da Cidade. In: PPLA 2010: SEMINÁRIO POLÍTICA E PLANEJAMENTO, 2., 2010, Curitiba. Anais. Curitiba: Ambiens, 2010.

BRAUN, R. Novos Paradigmas Ambientais: desenvolvimento ao ponto sustentável. $2 \mathrm{Ed}$. Petrópolis: Vozes, 2005. 192 p.

CUNHA, M. A. et al. Smart cities: transformação digital de cidades. São Paulo: Programa Gestão Pública e Cidadania PGPC, 2016.

CURY, M. J. F.; MARQUES, J. A. L. F. A Cidade Inteligente: uma reterritorialização. Redes, Santa Cruz do Sul, v. 22, n. 1, p. 102- 
117, dez. 2016. doi:

http://dx.doi.org/10.17058/redes.v22i1.8476.

DAVENPORT, Alan G.; GRIMMOND, Christine Susan B.; OKE, Tim R.; WIERINGA, Jon. Estimating the roughness of cities and sheltered country. $12^{\mathrm{a}}$ Conferência em Climatologia Aplicada, Asheville, American Meteorological Society. V. 4B, n.2, p. 96-99, 2000.

DIAS, R. C.; SEIXAS, P. C. Modelos regionais de governança da sustentabilidade: uma análise às primeiras estratégias integradas de desenvolvimento regional em Portugal. Revista Portuguesa de Estudos Regionais, n. 48, p. 5-16, 2018.

EDWARDS, B. Guía básica de la sostenibilidad. Barcelona: GG, 2008.

FERREIRA, H. V. L. Organização do espaço urbano e a estrutura térmica da cidade de Cuiabá-MT. 2019. 358 f. Dissertação (Pósgraduação em Geografia) - Universidade Federal de Mato Grosso, Cuiabá, 2019. doi: http://dx.doi.org/10.13140/RG.2.2.32551.500 87.

GUILHON, V. V. Indicadores de Sustentabilidade Urbana: Aplicação ao conjunto habitacional. Parque Residencial Manaus/AM. 2011. 217 f. Dissertação (Mestrado em Arquitetura e Urbanismo) Faculdade de Arquitetura e Urbanismo da Universidade de São Paulo, São Paulo, 2011. doi:10.11606/D.16.2011.tde-12012012140220.

KOMNINOS, N. Cidades Inteligentes: Sistemas de Inovação e Tecnologias da Informação ao serviço do Desenvolvimento das Cidades. 2008. Disponível em: http://www.urenio.org/wp-content/ uploads/2008/11/cidades-inteligentes.pdf. Acesso em: 15 set. 2020.

LINDSKOG, Helena. Smart Communities Initiatives. 2016. Disponível em: https://www.researchgate.net/publication/228
371789_Smart_communities_initiatives. Acesso em: 15 set. 2020.

LOPES, A. F. A. O programa cidade sustentável, seus indicadores e metas: Instrumentos Metodológicos para a Avaliação da Sustentabilidade no Município de Prata/MG. 2016. 203 f. Dissertação (Mestrado em Arquitetura e Urbanismo) - Universidade Federal de Uberlândia, Uberlândia, 2016.

NOBRE, M. Desenvolvimento sustentável: origens e significado atual. In NOBRE, M.; AMAZONAS, M. de C. Desenvolvimento sustentável: institucionalização de um conceito.. Brasília: Ibama, 2000.

PRESTES, M. F. Indicadores de Sustentabilidade em Urbanização sobre áreas de Mananciais: Uma aplicação do Barômetro da Sustentabilidade na ocupação do Guaratiba, município de Piraquara/PR. 2010. 190 f. Dissertação (Mestrado em Construção Civil) - Universidade Federal do Paraná, Curitiba, 2010.

SIEG. Sistema Estadual de Geoinformação. Base Cartográfica Municípios (2015). Disponível em: http://www2.sieg.go.gov.br/post/ver/199399/ municipios-2015. Acesso em setembro de 2020.

STEWART, I. D.; OKE, T. R. Local climate zones for urban temperature studies. Bulletin of the American Meteorological Society, v. 93, n. 12, p. 1879-1900, 2012. doi: https://doi.org/10.1175/BAMS-D-11-00019.1.

STRAPAZZON, C. Convergência tecnológica nas políticas urbanas: pequenas e médias "cidades inteligentes". Revista Jurídica, Curitiba, n. 22, p. 89-108, 2009. doi: http://dx.doi.org/10.21902/revistajur.2316753X.v22i6.104.

UNIVERSIDADE LUTERANA DO BRASIL (org.). Desenvolvimento e Sustentabilidade. Curitiba: Ibpex, 2009. 235 p 
WEISS, M. C.; BERNARDES, R. C.;

CONSONI, F. L. Cidades inteligentes como

nova prática para o gerenciamento dos

serviços e infraestruturas urbanos: a

experiência da cidade de Porto Alegre.

Revista Brasileira de Gestão Urbana, p. 310-

324, set./dez. 2015. Disponível em:

https://www.scielo.br/pdf/urbe/v7n3/2175-

3369-urbe-2175-3369007003AO01.pdf.

Acesso em: 05 set. 2020.

WOLFRAM, M. Deconstructing smart cities: an intertextual reading of concepts and practices for integrated urban and ICT development. In: REAL CORP, 2012, Schwechat. Proceedings. Schwechat: Competence Center for Urban and Regional Planning, 2012, p. 171-181. Disponível em: https://www.researchgate.net/publication/295 857818_Deconstructing_Smart_Cities_An_In tertextual_Reading_of_Concepts_and_Practic es_for_Integrated_Urban_and_ICT_Develop ment\#fullTextFileContent. Acesso em: 11 set. 2020. 